\title{
Time in an Aesthetic Experience of a cup of Sake
}

\author{
Hiroki Fukushima \\ Kyushu Women's University, 1-1, Jiyugaoka, Yahata-hnishi Ku \\ Kitakyushu City, Fukuoka, Japan
}

\begin{abstract}
There are two broad genres of artworks depending on the nature of their appreciation: arts of space and arts of time. In the aesthetic appreciation of taste, which is the focus of the experience of a cup of Sake? Is there the dimension of time in the experience of taste, and if so, what is it? Because taste has never been considered a formal subject of aesthetics, there is little discussion of describing and appreciating the aesthetic experience. This study deals with the concept of time in the appreciation of Sake, with some reference to the concept in narrative studies. As with wine, the time associated with Sake is multifaceted, and each is intrinsic to the aesthetic experience. Consider some examples: Time from the Sake is brewed to the time it is opened on the table (so-called "vintage"; for some years). The time from opening the bottle to pour into the glass (for minutes to tens of minutes). The time between pouring into the glass and entering the mouth (for a few minutes). Time to swallow in the mouth (a few seconds). The flavor felt after swallowing ("after flavor"; tens of seconds). This study focuses on the period from the Sake is placed in the mouth to the time it is swallowed. The purpose of this study is to reveal how time is narrated (explicitly or metaphorically) in the tens of seconds of a sake tasting.
\end{abstract}

Keywords: Sake, Taste, Temporal Arts, Plastic Arts.

\section{Introduction}

Taste has been largely neglected in traditional aesthetics. Since Sibley discussed the aesthetics of taste and smell in 1959, several philosophers have tried to theorize the aesthetics of taste and smell and have introduced artistic activities of smell, but not sufficient.

The few researchers who deal with the aesthetics of taste and smell must devote the early part of their works to a masochistic discussion of how taste and smell have been neglected in aesthetic research.

In this study, we temporarily put aside the question that whether taste and smell are the subjects of aesthetics. Then, if the art works of taste and smell are established, what kind of character they can have is discussed.

\section{The Temporal Art and the Spatial Art}

Consider the position of taste art. There are many genres in art such as painting, music, architecture, drama, literature, and so on. There is a long history of discussions on how to classify them systematically. Max Schasler (1819 -1903), a German philosopher, sets two opposing principles for the artworks: das Simultane and Sukzessive. The former corresponds to the plastic arts and the latter to temporal art. Architecture, sculpture, and painting are classified into plastic art, and music, mimic, and poetry are classified into temporal art. This classification is based on the conflict between material elements and ideological connotations.

The opposition between temporal art and spatial art was made clear in Lessing's (1729-1781) Laocoon: An Essay on the Limits of Painting and Poetry. In this debate, Lessing criticizes the tendency to equate poetry and painting, as typified by Horatius' proverb, "ut pictura poesis". The opposition between poetry and painting, he argues, is that painting and sculpture depict the decisive moment of a subject in a spatial extension, while literature depicts a story in a temporal extension. If we follow Lessing's argument, spatial art can be further divided into two categories: three-dimensional (e.g.,

(C) The 2021 International Conference on Artificial Life and Robotics (ICAROB2021), January 21 to 24, 2021 
architecture and sculpture) and two-dimensional (e.g., painting).

The classification of temporal art and spatial art may seem unassailable, but E. Souriau argued against it. Souriau criticizes the disconnection between temporal and spatial art. In his main work, La Correspondance des arts (1943), he compares music and painting, and points out the similarities between their various elements.

\section{Taste and The Genre of the art}

Expressions of taste can be broadly classified into verbal and non-verbal expressions. Verbal expressions are, as typified by sommeliers, the descriptions of the characters and impressions of a taste experiences. Linguistic data can be collected from publications such as books and magazines, or through verbalization experiments and interviews.

There are few practical attempts of non-verbal expression of taste. In the narrower sense, non-verbal expression can be defined as a work of art in which a person draws a picture or plays music to describe the flavors of all along the time a wine enters the mouth to the time it is swallowed. Such artworks will express a single, subjective, individual experience of eating and drinking. On the other hand, in a broader sense, non-verbal expression can include labels, posters, and commercial images of luxury goods such as wine, sake, cigarettes, etc. These can be thought of as depictions of the character of the flavors of the product, but they do not represent a specific eating or drinking experience. The fact that a bear is depicted on a chocolate package does not mean that the chocolate tastes like bear meat.

\subsection{Multiple Time aspect in the Appreciation of Taste}

In this section, I will analyze how time is discussed in the representation of taste.

In the appreciation of taste, the most crucial time is the few seconds between when the food enters the mouth and when it is swallowed into the back of the throat. However, those few seconds are only a small part of the many aspects of the concept of time relating to the appreciation of taste.

As with wine, the time associated with Sake is multifaceted, and each is intrinsic to the aesthetic experience:
- The time between when the liquor is brewed and when it is opened on the table. (so-called "vintage" for some years).

- The time from opening the bottle to pour into the glass (for minutes to tens of minutes).

- The time between pouring into the glass and entering the mouth (for a few minutes).

- Time to swallow in the mouth (a few seconds).

- The flavor felt after swallowing ("after flavor"; tens of seconds).

Among these time aspects, this study focuses on the period from the Sake is placed in the mouth to the time it is swallowed.

\subsection{Describing the Time of the Taste}

Case 1: Dominio IV in Oregon
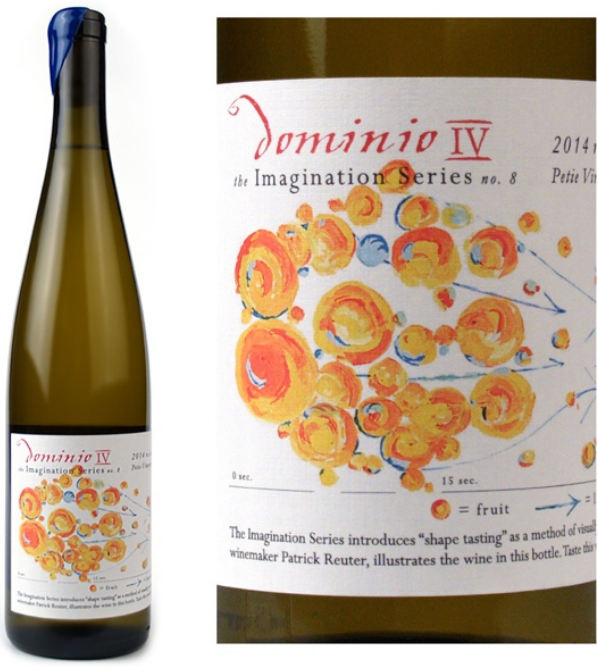

Figure 1. Riesling 2014, Dominio IV

Oregon winery Dominio IV's imagination series features taste drawings on wine labels. In this drawing, called "shape tasting," the impression of taste is represented by a two-dimensional picture along a time axis. The shapes and colors of the drawing synaesthetically represent the taste elements of the wine. The time axis and the number of seconds are at the bottom of the painting. The time goes from left to right, symbolically depicting the flavors 
as they appear, spread, move, unfold, change, and linger in the mouth.

At first glance, it appears as if the artist is freely drawing the flavor images with paint, but in this series, the vertical and horizontal axes of the canvas are defined first. The wine label is oriented horizontally, and the horizontal axis direction is a time axis with seconds. In the picture of Riesling shown in Figure 4, the leftmost point is 0 seconds, and the changes in taste over 60 seconds are drawn in 15-second increments. The vertical axis is shown as the extent of the palate breadth. The middle of the vertical axis represents the center of the oral cavity. The $1 / 4$ width range from the center is depicted as the "narrow" area. The outer drawing area shows how wide the flavor spreads. Thus, in the example of fig. 1, a time variation can be seen as follows; the flavor first spreads widely in the mouth -> gradually converges narrowly from 15 seconds to 30 seconds -> leading to the final taste. In the imagination series, the drawings are described vertically symmetrically, with some exceptions.

In addition to the time axis and the spatial axis of the oral cavity, another feature is that what the shapes (i.e., circles, lines, and arrows in the drawings) represent are defined. Again, in figure 1, the example of Riesling 2014, we can see a note at the bottom of the figure. According to the notation, the red circles represent "fruit" flavors, and the yellow curve represents "fruit-based acidity." Then, the brownish arrows indicate "linear acidity."

In this way, the definitions of the drawing elements enable us to decode the drawings. The 2014 Riesling is expected to taste as follows; fruit-based acidity and sweet fruit flavors that fill the mouth as soon as you put it in -> and then gradually fade after about 15 seconds $->$ After 30 seconds, a linear acidity emerges - $>$ a lingering acidity can be enjoyed from 45 to 60 seconds."

The expression of wine flavor is often given in a language-based manner, as typified by sommeliers. And such descriptions are often printed on the back labels of wines. In the Imagination Series of Dominio IV, captions are provided just below the illustrations. Additionally, verbal explarnations of the flavors are also provided. This series is an eloquent example of the possibility of the non-verbal description of the taste.

Case 2: Sake Art Label Project

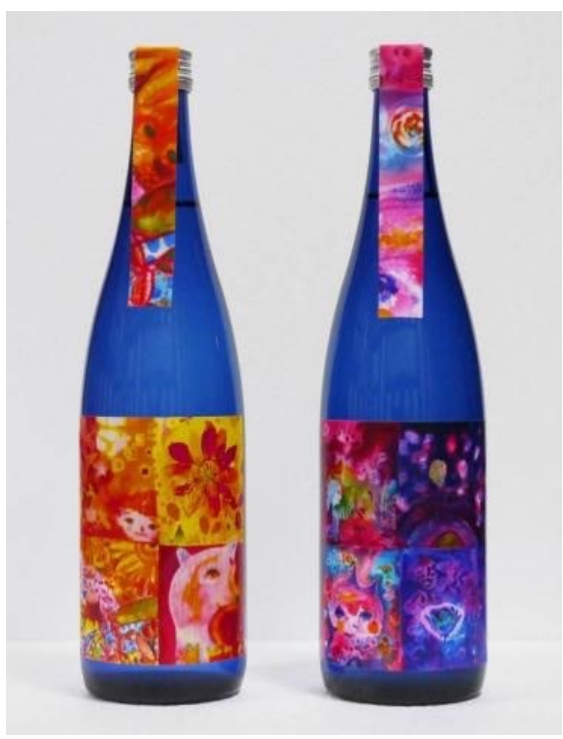

Figure 2, Sake Art Label project

The attempt to present the image of taste in pictorial form has also been practiced in sake.

In the past, sake labels were generally designed by selecting a background from a template and placing the brush-written brand name. In recent years, however, with the development of distribution and the boom in local sake and ginjo sake, stylish and unique designs have been seen on sake labels. This shift represents a turning point. Up until now, it was enough to know the name of the brand in order to select the "usual" sake from the local brewery, such as Tsukasa-Botan or Tosatsuru in Kochi Prefecture. But now, with the development of transportation, consumers tend to seek unique local sake all over Japan.

Against such a background, it has become common for sake breweries to express their thoughts and the characters of their brand into their label design.

One of the notable efforts to express the image of sake flavor through labels is the "Sake Art Label Project," which was realized in 2014 through a collaboration between the Obata Shuzo Brewery (Sado City, Niigata Prefecture, the representative brand "Manotsuru") and the Isetan Mitsukoshi Group (Figure 6).

The project is an effort to break away from the former sake labels style, as a list of technical terms and express the image of flavor as an art label. Sake labels generally contain not only the name of the brand but also the variety of rice, such as "Yamadanishiki," the standard, such as

(C) The 2021 International Conference on Artificial Life and Robotics (ICAROB2021), January 21 to 24, 2021 
"Junmai" or "Ginjo," the method of production, such as polishing ratio or "Namagenshu," and numerical values, such as amino acid content or alcohol content. While this information is useful for predicting the flavor, it also requires a certain level of knowledge to decipher, which can put off beginners.

In the sake art label project, the opinion exchange meeting which invited cooking party, copywriter, and general consumers was carried out, and 8 kinds of sake were tasted blindly (concealed brand names). About 40 participants answered a questionnaire to answer images, colors, and objects associated with each brand according to their preferences. At the tasting site, Takeshi Hirashima, an illustrator, was present and drew illustrations based on the comments of the participants. Finally, the brewery, the buyer of Isetan Mitsukoshi, and the illustrator selected the two highly evaluated brands, and the illustrator designed the images of each flavor on the labels.

\section{Conclusion}

The characteristic of painting is that it has no temporality. Of course, some philosophers such as Souriau insist on the concept of time in paintings. And in the plastic arts, aesthetic experiences can occur chronologically. However, unlike music, the object itself does not change its form in time.

There are many efforts to express time on canvas. These efforts are not avant-garde. Manga uses a method of developing time through the combination of multiple panels of pictures. Or the illustrated handscrolls "Emaki-mono" (literally 'picture-scrolls'), traditionally produced in Japan and China, are pictorial artworks in which the story unfolds chronologically. The oldest picture scrolls in Japan date back to the Nara period (Einga-kyo, 7C-8C). From the 10th century onward, picture scrolls have been actively produced in Japan in various genres, including war stories, diaries, fairy tales, and comic stories. Anna Willmann points out that; Reading a handscroll can become an almost cinematic Anna Willmann points out that; Reading a handscroll can become an almost cinematic experience as the viewer scrolls through a narrative from right to left, rolling out one segment with his left hand as he re-rolls the righthand portion.

\section{Acknowledgements}

This work was supported by JSPS KAKENHI Grant Number 20K20127.

\section{References}

1. Lessing, G. E. (1853). Laocoon: an Essay on the Limits of Painting and Poetry. Longman, Brown, Green, and Longmans.

2. Souriau, E. (1949). Time in the Plastic Arts. The Journal of Aesthetics and Art Criticism, 7(4), 294-307. doi:10.2307/426722 